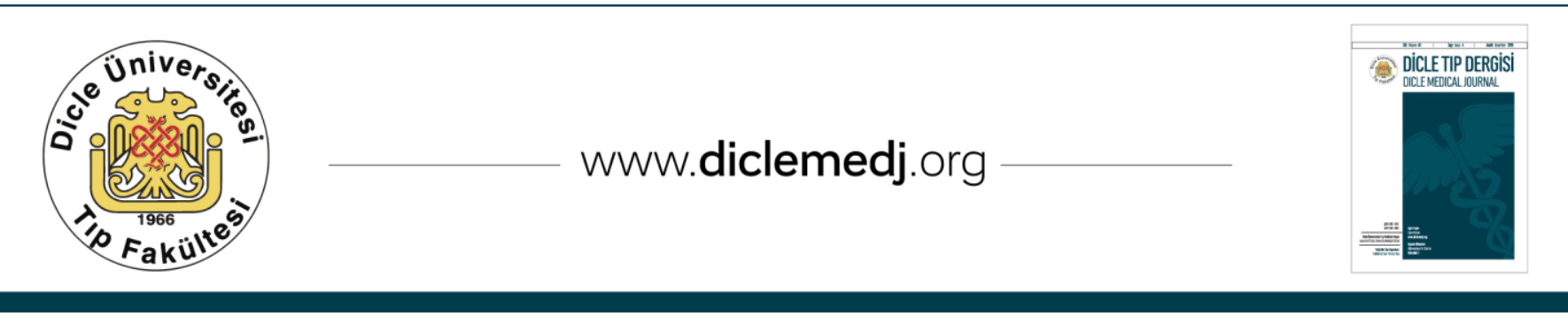

Olgu Sunumu / Case Report

\title{
Psödohipoparatiroidi Tip 1A: Olgu Sunumu
}

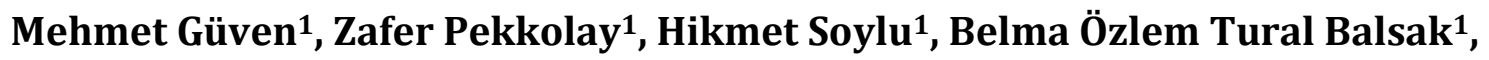 \\ Alpaslan Kemal Tuzcu' ${ }^{1}$
}

1 Dicle Üniversitesi Tıp Fakültesi Endokrinoloji ve Metabolizma Hastalıkları Bilim Dalı Diyarbakır, Türkiye

Geliș: 06.12.2016 Revizyon: 27.02.2017 Kabul Tarihi: 17.03.2017

\section{Özet}

Psödohipoparatiroidizm (PHPT); hedef organın parathormona (PTH) yanıt vermediği kalıtımsal bir bozukluktur. Biyokimyasal olarak; hipokalsemi, hiperfosfatemi ve PTH yüksekliği ile karakterizedir. PTH uygulamasına verilen yanıt belirgin derecede düşüktür. Tip 1A, biyokimyasal özelliklere ek olarak Albright herediter osteodistrofisi (AHO) olarak bilinen karakteristik somatik bir fenotipe de sahiptir. Bu fenotipin, kısa boy, yuvarlak yüz, frontal bombelik, brakidaktili, obezite özelikleri bulunmaktadır. Burada biz, hipokalsemi ve Albright herediter osteodistrofisi tanısı koyduğumuz; kalsiyum, aktif D vitamini ile tedavi ettiğimiz olgumuzu sunduk.

Anahtar kelimeler: Psödohipoparatiroidi, hipokalsemi, Albright herediter osteodistrofisi

\section{Pseudohypoparathyroidism Type 1A: Case Report}

\begin{abstract}
Pseudohypoparathyroidism (PHPT); is a hereditary disorder in which the target organ does not respond to parathormone (PTH). Biochemically; it is characterized by the hypocalcemia, hyperphosphatemia, and elevated PTH. The response to PTH administration is markedly lower. In addition to it's biochemical properties, Type $1 \mathrm{~A}$ also has a characteristic somatic phenotype known as Albright hereditary osteodystrophy (AHO). This phenotype is characterized by short stature, round face, frontal bubble, brachydactyly, obesity. Here, we present a patient, diagnosed with Albright's hereditary osteodystrophy and hypocalcemia that is treated by calcium, vitamin D .
\end{abstract}

Keywords: Pseudohypoparathyroidism, hypocalsemia, Albright's hereditary osteodystrophy

DOI: $10.5798 /$ dicletip.319782

Yazışma Adresi / Correspondence: Mehmet Güven, Dicle Üniversitesi Tıp Fakültesi Endokrinoloji ve Metabolizma Hastalıkları Bilim Dalı 21070 Sur,

Diyarbakır, Türkiye e-mail: dr.mguven@gmail.com 


\section{GíRiş}

Psödohipoparatiroidizm ; parathormona hedef organ yanıtsızlığı olan otozomal dominant geçişli bir genetik bozukluktur. Prevalansı tam bilinmemektedir. Psödohipoparatiroidizmde biyokimyasal olarak parathormon eksikliği durumuna benzer şekilde hipokalsemi, hiperfosfatemi olur, ancak doku düzeyinde yanıtsızlığa sekonder PTH düzeyi yüksektir ve dışarıdan verilen $\mathrm{PTH}^{\prime}$ ye de yanıt alınamaz. Tip-1 (A, B, C ) ve Tip-2 olmak üzere başlıca 3 formu bulunmaktadır ${ }^{1,2}$.

Parathormona duyarlı ileti sistemi; reseptör, adenil siklaz ve G-proteini olmak üzere üç kısımdan oluşur. G-proteinin görevi; PTH'yi hücre duvarındaki reseptörlere bağlayarak cAMP'yi aktive etmektir. Tip 1 PHPT de PTH' a cAMP yanitı yoktur. Tip 2 de ise cAMP'nin böbrek tubulus hücreleri üzerindeki biyolojik etkisi eksik olduğundan fosfatüri yanıtı yoktur ${ }^{3,4}$. Hastalığın tüm formlarında G-protein geninin (GNAS1 gen) mutasyonları saptanmıștır ${ }^{5}$. Tip-1A'da G-protein aktivitesi düşüktür. PTH yanında TSH, FSH, LH, glukagon gibi diğer hormonlara da direnç olabilir. Tip 1B'de G protein aktivitesi normaldir. Hedef dokularda PTH'a direnç varken diğer hormonlara yoktur. Fenotipik olarak normaldir. Tip 1-C' de G protein aktivitesi normal ancak diğer hormonlara karşı direnç vardır ${ }^{6,7}$.

Tip 1A Albright'ın herediter osteodistrofisi olarak bilinmekte olup, klinikte karakteristik olarak kısa boy, yuvarlak yüz, frontal bombelik, obezite, brakidaktili, hipokalsemi ve hiperparatiroidi görülebilir. Birçok hastada tirotiropin direnci nedeniyle hipotiroidi ve daha nadir olarak ta gonadotropin direnci nedeniyle hipogonadizm mevcuttur. Olguların yaklașık yarısı mental retardedir. Tip-1A, PHP'li hastaların yaklaşık 50'sini oluşturmaktadır ${ }^{1}$.

Burada hipokalsemi, hiperfosfatemi saptadığımız tipik AHO fenotipi gösteren, doku düzeyinde PTH direnci olan vakamızın kalsiyum ve aktif D vitamini tedavisi sonrası klinik ve biyokimyasal olarak hızlı bir düzelme gösterdiğini sunmak istedik.

\section{OLGU SUNUMU}

31 yaşında bayan hasta, polikliniğimize ellerde ve ayaklarda uyuşma nedeniyle başvurdu. Özgeçmişinde daha önce bilinen kronik bir hastalığı veya ilaç kullanım öyküsü yoktu. Çocukluk yaşlarından beri ellerde ve ayaklarda uyuşma şikayeti mevcuttu. Soy geçmişinde anne-babada akraba evliliği olduğu, bir abisin de kendisi gibi dış görünüşe sahip olduğunu belirtti. Fizik muayenede; boyu $150 \mathrm{~cm}$, ağırlık $66 \mathrm{~kg}$, vücut kitle indeksi $29.3 \mathrm{~kg} / \mathrm{m} 2$ idi. Boy kısalığı, yuvarlak yüz, frontal bombelik, brakidaktili dikkat çekmekteydi (Resim1). Chowastek ve Trousseau bulguları pozitifti. Kardiyovasküler sistem, solunum sistemi ve batın muayenesi normaldi.

Resim 1: Karakteristik dış görünüşü : yuvarlak yüz, frontal bombelik, ekstremitelerde kısalık göze çarpmaktadır.

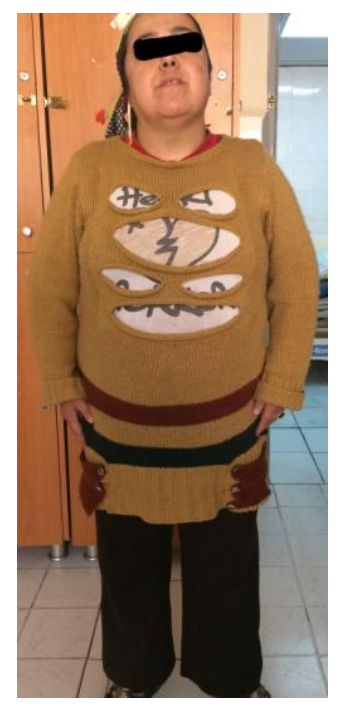

Yapılan kan tetkiklerinde; kalsiyum: $7.7 \mathrm{mg} / \mathrm{dl}$ (8.4-10.2 mg/dl) , fosfor: $4.9 \mathrm{mg} / \mathrm{dl}(2.5-4.5$ $\mathrm{mg} / \mathrm{dl})$, albumin:4 $\mathrm{gr} / \mathrm{dl} \quad(4-5 \mathrm{gr} / \mathrm{dl})$, parathormon: $112 \mathrm{pg} / \mathrm{ml}(15-65 \mathrm{pg} / \mathrm{ml})$,D vitamini: $54 \mu \mathrm{g} / \mathrm{L}(10-60 \mu \mathrm{g} / \mathrm{L})$,TSH: 0.88 $\mathrm{uIU} / \mathrm{mL}(0.27-4.2 \mathrm{uIU} / \mathrm{mL})$, serbest T4: 14.63 $\mathrm{pmol} / \mathrm{L}$ (12-22 pmol/L), serbest T3: 4.73 pmol/L (3.9-6.7 pmol/L), LH: $8.41 \mathrm{mIU} / \mathrm{ml}$ (foliküler faz 2.4-12.6 mIU/ml), FSH: 5.83 
$\mathrm{mIU} / \mathrm{ml}$ (foliküler faz: $3.5-12.5 \mathrm{mIU} / \mathrm{ml}$ ), estradiol: $111.8 \mathrm{pg} / \mathrm{mL}$ ( foliküler faz 12.5-166 $\mathrm{pg} / \mathrm{mL}$ ), progesteron $0.1 \mathrm{ng} / \mathrm{mL}$ (foliküler faz 0.2-1.4 ng/mL) saptand. Hemogram, ürekreatinin değerleri normal bulundu. 24 saatlik idrarda kalsiyum atılımı $<48 \mathrm{mg} / \mathrm{dl}$ idi. Mevcut kan tetkiklerinde hipokalsemi, hiperfosfatemi, hiperparatiroidi göze çarpmaktayd. El grafilerinde beşinci metakarpal kemiklerde; ayak grafilerinde üç, dört, beşinci metatarsal kemiklerde kısalık saptandı (Resim 2-3). Çekilen kranyal bilgisayarlı tomografide bilateral bazal ganglionlarda daha belirgin ve daha yaygın olmak üzere plak tarzında kalsifikasyonlar saptandı (Resim 4).

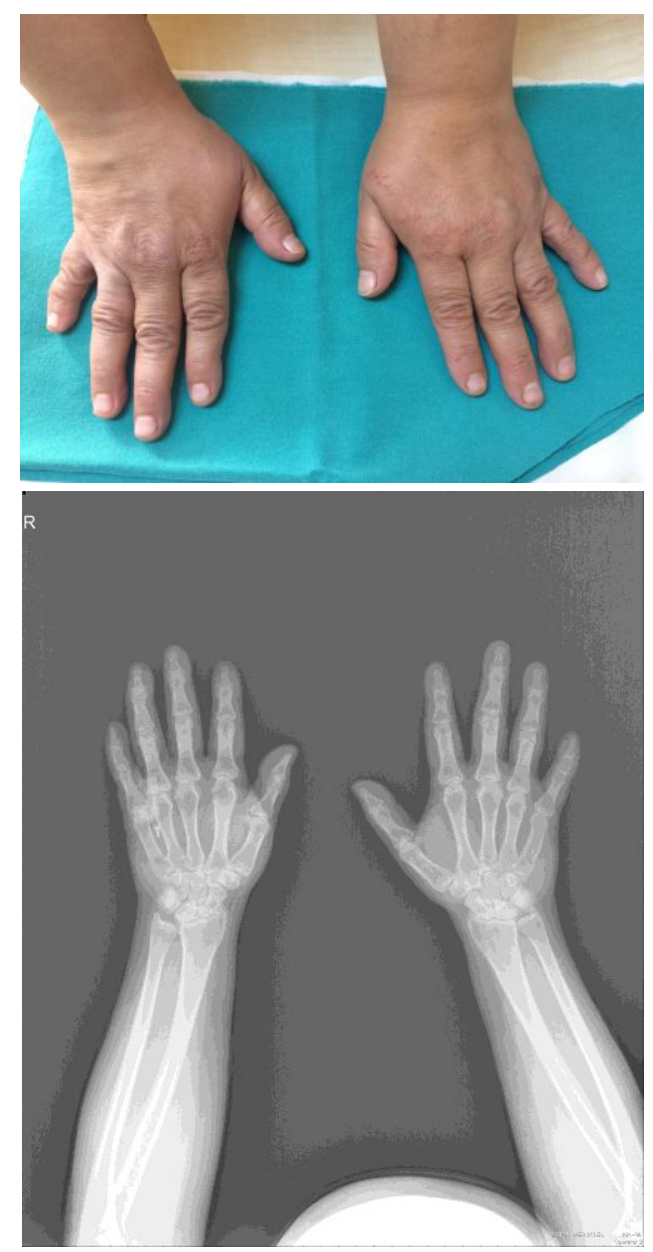

Resim 2a+2b:Kısa olan beşinci el parmağı ve radyolojik görüntüsü
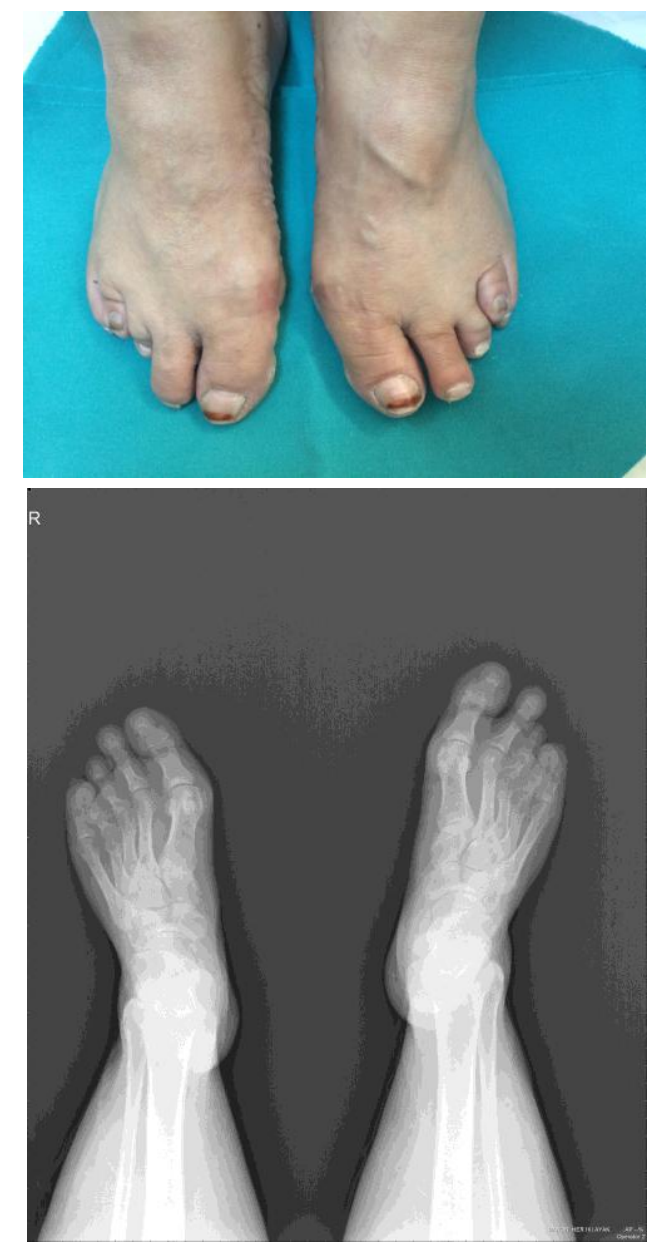

Resim 3a+3b:Kısa olan 3, 4, 5. ayak parmakları ve radyolojik görüntüsü

Hipokalsemiye bağlı kasılmaları mevcut olan hastaya parenteral 2 ampul \%10 kalsiyum glukonat $\% 5$ dekstroz içerisinde verildi ve kalsitriol 0.5 mcg $2 \times 1$ tablet başlandı.Tedavinin 2. gününde aktif $\mathrm{D}$ vitamini ve kalsiyum tedavisi ile olgunun yakınmalarının geçtiği, latent tetani göstergesi olan Chowastek ve Trousseau bulgularının kaybolduğu ve laboratuvar bulgularında düzelme olduğu gözlendi. Düzeltilmiş kalsiyum seviyesi $8.3 \mathrm{mg}$ /dl seviyesine yükseldi. Tedavi sonrası hastanın şikayetleri geriledi. Klinik iyileşme sağlanan hastaya $1000 \mathrm{mg}$ kalsiyum +880 IU vitamin D3 effervesan tablet $2 \times 1$, kalsitriol 0.5 mcg kapsül $2 \times 1$ verilerek poliklinik kontrolüne gelmek üzere taburcu edildi. 


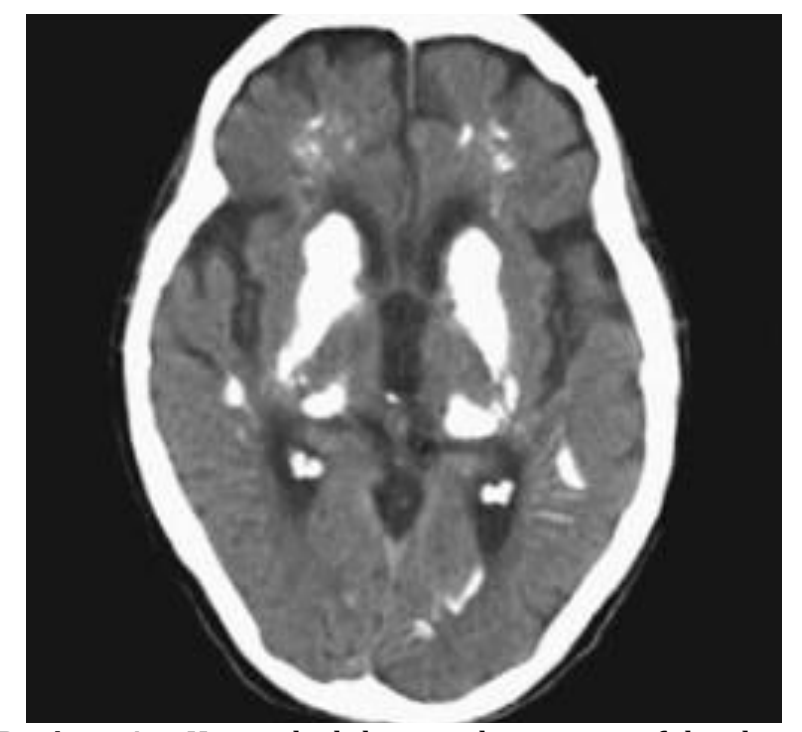

Resim 4: Kranyal bilgisayarlı tomografide bazal ganlionlarda belirgin olmak üzere yaygın kalsifikasyonlar görülmektedir.

\section{TARTIŞMA}

Hipokalsemi, hiperfosfatemili bir hastada ürekreatinin değerleri normal iken PTH seviyesi normal veya düşük beklenir. Bizim olgumuzda düzeltilmiş kalsiyum seviyesi $7.7 \mathrm{mg} / \mathrm{dl}$, fosfor $4.9 \mathrm{mg} / \mathrm{dl}$ iken PTH seviyesi 112 pg/ml olarak bulundu. Bu duruma doku düzeyinde $\mathrm{PTH}^{\prime}$ ya direnç gelişmesiyle, PTH seviyesi yüksek bulunur. D vitamini eksikliğinde hipokalseminin yanında fosfor düzeyi de düşük veya normalin alt sinırındadır. Bizim olgumuzda D vitamini seviyesi normal aralıktaydı. Tedavi sonrası hedef kalsiyum seviyesi normalin alt sinırında, 8-8.5 mg/dl arası hedeflenmelidir. Çoğu hasta bu seviyelerde asemptomatik seyreder. Daha yüksek kalsiyum seviyeleri hiperkalsiüriye neden olabilir. $\mathrm{Bu}$ da nefrokalsinozis, nefrolitiyazis riskini arttırır ${ }^{8}$.

G-protein aktivitesinin eksikliği generalize hücresel bir bozukluk olușturmaktadır ki, bu eksiklik adenil siklaz sistemi ile çalışan TSH, LH, FSH ve glukagon gibi hormonlara da direnç gelişimine yol açar. Bu durum Tip-1A PHP ile birlikte görülen diğer endokrin patolojilerden de sorumludur'. Olgumuzda TSH, FSH, LH seviyeleri normal aralıktaydı. Diğer hormonlara direnç saptanmadı.
PHPT 1A, biyokimyasal özeliklere ek olarak Albright herediter osteodistrofisi olarak bilinen karakteristik bir fenotipe de sahiptir. Kısa boy, yuvarlak yüz, frontal bombelik brakidaktili, metatarslarda kısalma, cilt altı ossifikasyonları görülebilir4. Bizim olgumuz belirtilen AHO fenotipine uymaktaydı. Kısa boy, frontal bombelik, yuvarlak yüz dikkati çekmekteydi. Brakidaktili, metakarp ve metatars kemiklerde kısalık mevcuttu.

PHPT' de birçok dokuda kalsifikasyon gözlenebilmektedir. Kalsifikasyonlar sıklıkla beyin, subkutan doku ve kalpte izlenmektedir. Erişkin hastaların yaklaşık \%100'de beyinde bazal ganglionlarda kalsifikasyonlar görülmektedir ${ }^{10-11}$. Hastamızın kranyal bilgisayarlı tomografisinde bilateral bazal ganglionlarda daha belirgin olmak üzere yaygın kalsifikasyonlar gösterilmiştir.

Sonuç olarak, hipokalsemi ve hiperfosfatemi ile gelen PTH yüksek ve karakteristik fenotipik görünümü olan hastalarda psödohipoparatiroidi tip $1 \mathrm{~A}$ düşünülmelidir. Gereğinde önce parenteral sonrasında oral yoldan Ca ve D vitamini ile uygun replasman tedavisi ömür boyu verilmelidir. Ca değerleri, replasmanda hiçbir zaman normale çıkarılmaya çalışılmamalı, metastatik kalsifikasyonlardan hasta korunmaya çalışılmalıdır.

Not: Hastadan görsel ve klinik verilerinin kimliğini açı etmeyecek şekilde yayınlanması için sözel ve yazılı onay alınmıştır.

Çıkar Çatışması Beyanı: Yazarlar çıkar çatışması olmadığını bildirmişlerdir.

Finansal Destek: Bu çalışma her hangi bir fon tarafından desteklenmemiştir.

Declaration of Conflicting Interests: The authors declare that they have no conflict of interest.

Financial Disclosure: No financial support was received. 


\section{KAYNAKLAR}

1. Doyle DA, Digeorge AM. Pseudohypoparathyroidism (Albright hereditary osteodystrophy). In Kliegman RM, Behrman RE, Jenson HB, Stanton BF (eds). Nelson Textbook of Pediatrics, 18th ed. Philadelphia, Saunders Co; 2007; 2344-5.

2. Goswami M, Verma $M$, Singh A, et al. Albright hereditary osteodystrophy: a rare case report. J Indian Soc Pedod Prev Dent 2009; 27: 184-8.

3. Bringhurst FR, Demay MB, Kronenberg HM: Hormones and disorders of mineral metabolism. In: Williams Textbook of Endocrinology. 9th ed. WB Saunders Company, 1998: 1155-1209.

4. Maeda SS, Fortes EM, Oliveira UM, et al. Hypoparathyroidism and pseudohypoparathyroidism. Arq Bras. Endocrinol Metabol 2006; 50: 664-73.

5. Weinstein LS, Gejman PV, Friedman E et al. Mutations of the Gs -subunit gene in Albright hereditary osteodystrophy detected by denaturing gradient gel electrophoresis. Proc Natl Acad Sci US A 1990; 87: 8287-90.

6. Ally MR, Bernet VJ, Atwood JE. Visual vignette. Type 1A pseudohypoparathyroidism. Endocr Pract 2008; 14: 952-3.
7. Levine M. Hypoparathyroidism and pseudohypoparathyroidism. In: DeGroot LJ, Jameson JL. Endocrinology, 4thed. Philadelphia: WB Saunders, 2001. pp. 1133-53.

8. Spiegel AM. Hypercalcemia and Hypocalcemia. In Wyngaarden JB, Smith LH, BennettJC (eds). The Parathyroid Glands, Philadelphia, Saunders Company 1992: 1418-20.

9. Levine MA. Clinical Review: Pseudohypoparathyroidism: From bedside to bench and back. J Bone Miner Res 1999; 14: 1255-60.

10. Sachs C, Sjoberg HE, Ericson K. Basal ganglion calcification onCT :relation to hypopara-thyroidism. Neurology 1982;32:779-82.

11. Faissolle $\mathrm{P}$, Wagner-Mahler K, Mas JC, at al. A cause of intracerebral calcifications that should be known: pseudohypoparathyroidism Ib. Arch Pediatr 2008;15:1433-6. 